This item was submitted to Loughborough's Research Repository by the author.

Items in Figshare are protected by copyright, with all rights reserved, unless otherwise indicated.

\title{
Synthesis and fluorescence emission properties of 1,3,6,8-tetraarylpyrenes
}

PLEASE CITE THE PUBLISHED VERSION

http://dx.doi.org/10.1016/j.molstruc.2013.04.074

\section{PUBLISHER}

(C) Elsevier B.V.

\section{VERSION}

AM (Accepted Manuscript)

\section{PUBLISHER STATEMENT}

This work is made available according to the conditions of the Creative Commons Attribution-NonCommercialNoDerivatives 4.0 International (CC BY-NC-ND 4.0) licence. Full details of this licence are available at: https://creativecommons.org/licenses/by-nc-nd/4.0/

\section{LICENCE}

CC BY-NC-ND 4.0

\section{REPOSITORY RECORD}

Hu, Jian-Yong, Xing Feng, Hirotsugu Tomiyasu, Nobuyuki Seto, Ummey Rayhan, Mark R.J. Elsegood, Carl Redshaw, and Takehiko Yamato. 2019. "Synthesis and Fluorescence Emission Properties of 1,3,6,8tetraarylpyrenes". figshare. https://hdl.handle.net/2134/18276. 


\title{
Synthesis and fluorescence emission properties of $\mathbf{1 , 3 , 6 , 8 -}$ tetraarylpyrenes
}

\author{
Jian-Yong Hu ${ }^{\mathrm{a}}$, Xing Feng ${ }^{\mathrm{a}}$, Hirotsugu Tomiyasu ${ }^{\mathrm{a}}$, Nobuyuki Seto ${ }^{\mathrm{a}}$, Ummey Rayhan ${ }^{\mathrm{a}}$, \\ Mark R. J. Elsegood ${ }^{\mathrm{b}}$, Carl Redshaw ${ }^{\mathrm{c}}$ and Takehiko Yamato ${ }^{\mathrm{a}}{ }^{*}$
}

a Department of Applied Chemistry, Faculty of Science and Engineering, Saga University, Honjo-machi 1, Saga-shi, Saga 840-8502, Japan

${ }^{\mathrm{b}}$ Chemistry Department, Loughborough University, Loughborough, LE11 3TU, UK.

${ }^{\mathrm{c}}$ Department of Chemistry, The University of Hull, HU6 7RX, UK

\begin{abstract}
Three types of stable pyrene-based highly fluorescence (blue) compounds, 1-, 1,6-bis, 1,8bis and 1,3,6,8-tetrakis(7-tert-butylpyrenyl)pyrenes and 1,3,6,8-tetrakis[9,9-bis(3methylbutyl)-9H-fluoren-2-yl]pyrene, were successfully synthesized via a $\mathrm{Pd} / \mathrm{Cu}$-catalysed Suzuki cross-coupling reaction of the corresponding bromopyrenes with 7-tert-butyl-1pyrenylboronic ester or 2-[9,9-bis(3-methylbutyl)-9H-fluoren-2-yl]-4,4,5,5-tetramethyl$[1,3,2]$ dioxaborolane, respectively. All compounds have good solubility (in what?) and high thermal stability with melting points up to $270{ }^{\circ} \mathrm{C}$; the exceptions are the isomeric 1,6-bis-, and 1,8-bispyrenyl-substituted pyrenes. All products show high extinction coefficients of absorption $\left(\lambda_{\max } \approx 349-396 \mathrm{~nm}\right.$ ) and high quantum yields $\left(\lambda_{\max } \approx 432-465\right.$ $\left.\mathrm{nm} ; \Phi_{\mathrm{f}} \approx 0.75-0.99\right)$ in dichloromethane solution, and emit strong fluorescence in the visible region ranging from deep-blue to pure-blue on increasing the number of substituents. This data suggests that such systems have promise as blue emitters in organic light-emitting device (OLED) applications. (OLED = organic light emitting diode). Crystal structures were determined for 1,3,6,8-tetrakis-[9,9-bis(3-methylbutyl)-9H-fluoren-2yl]pyrene and 1,3,6,8-tetrakis(4-methoxyphenyl)pyrene.
\end{abstract}

Keywords: Pyrene, Suzuki cross-coupling reaction, Tetraarylpyrenes, Tetrafluorenylpyrenes, Fluorescence emission properties 
Corresponding author. Tel.: +81 95228 8679; fax: +81 95228 8548. E-mail address: yamatot@cc.sagau.ac.jp (T. Yamato)

\section{HIGHLIGHT}

- A series of 1,3,6,8-tetraarylpyrenes have been synthesized in high yields by the Suzuki cross-coupling reaction.

- All compounds emit very bright fluorescent emissions, from deep-blue to pure-blue in solution $\left(\Phi_{\mathrm{f}}=0.75-0.99\right.$ in dichloromethane $)$.

- Tetrapyrenyl and tetrafluorenyl groups suppress $\pi \cdots \pi$ stacking in the solid state. 


\section{Introduction}

Organic light-emitting devices (OLEDs) have seen remarkable development in the past two decades due to their potential application in full-color flat-panel displays and solidstate lighting [1-4]. The three primary colors of red, green and blue (RGB) are essential for full-color displays. However, compared to red and green-based OLEDs, blue OLEDs show relatively poor performance due to the intrinsic wide-energy band-gap nature of blue emitters. Thus, blue emitting compounds with good color purity and high efficiency are particularly worthy of study.

Organic compounds such as polycyclic aromatic hydrocarbons (PAHs) (e.g. naphthalene, anthracene, pyrene, perylene, etc.) and their derivatives are suitable for developing RGB emitters for OLED applications owing to their excellent fluorescent properties [5-10]. In particular, these compounds have strong $\pi$-electron delocalization characteristics and can be substituted with a range of functional groups, which may be used for OLED materials with a tunable wavelength. Numerous RGB emitting compounds derived from naphthalene, anthracene, perylene and fluorene have been widely reported for OLED applications. However, the use of pyrene and its derivatives as blue emitters in OLEDs is limited because of the formation of $\pi$-aggregates/excimers in solution at high concentration and in the solid-state, which can lead to additional long-wavelength emission and a decrease of fluorescence quantum yield. This problem has been mainly solved by the introduction of bulky or heavily branched side chains into the pyrene molecule or co-polymerization with a suitable bulky co-monomer. Recently, it was reported that pyrene derivatives could be used as blue-emitting compounds in OLEDs via the introduction of long or branched side chains [11-15]. Furthermore, the synthesis of a pyrene-based fluorescent dendrimer has also been reported, wherein the core unit is a 
1,3,6,8-tetrasubstituted pyrene and the peripheral units contain monosubstituted pyrene units $[11,16-21]$.

On the other hand, fluorene is a PAH molecule with a rigid biphenyl plane. The C9 site of the fluorene molecule can be easily functionalized, which provides for the possibility of improved solubility and processability, and of controlling the excimer formation in the excited state [22-24]. Recently, fluorene-based compounds have been extensively used as thermally stable and efficient emissive OLED materials [25-29] and as high carrier transport organic field-effect transistors (OFETs) material [30-32].

In this study, pyrene was chosen as a $\pi$-conjugation center core because of its excellent fluorescence properties [33], its electron-acceptor nature [34,35], and its good performance in solution [36]. Substituted fluorenyl groups were introduced into pyrene molecules to invoke high solution and solid-state photoluminescence (PL) quantum yields [35], and in order to block the inter-chain interactions. To improve solubility and thermal stability, two long alkyl groups were introduced at the C9 position of the fluorene moiety $[37,38]$. The substituted pyrenyl groups were introduced because they are highly emissive, bulky, and rigid, and were expected to improve the fluorescence quantum yield and thermal stability. We were interested in investigating the structure-property relationships between the $\pi$ center pyrene core and the increasing number of substituents or the use of different substituents. Thus, we report herein the synthesis and fluorescence emission properties of 1-, 1,6-bis-, 1,8-bis- and 1,3,6,8-tetrakis-(7-tert-butylpyrenyl)- pyrenes and 1,3,6,8tetrakis[9,9-bis(3-methylbutyl)-9H-fluoren-2-yl]pyrene.

\section{Experimental}

The ${ }^{1} \mathrm{H} /{ }^{13} \mathrm{C}$ NMR spectra were recorded at $300 \mathrm{MHz}$ and $75 \mathrm{MHz}$ on a Nippon Denshi JEOL FT-300 NMR spectrometer in $\mathrm{CDCl}_{3}$ with $\mathrm{Me}_{4} \mathrm{Si}$ as an internal reference. The IR spectra were obtained as KBr pellets on a Nippon Denshi JIR-AQ2OM spectrometer. Mass spectra were obtained on a Nippon Denshi JMS-HX110A Ultra-high Performance Mass 
Spectrometer at $75 \mathrm{eV}$ using a direct-inlet system. Elemental analyses were performed by Yanaco MT-5. Gas-liquid chromatograph (GLC) analyses were performed by Shimadzu gas chromatograph, GC-14A; silicone OV-1, $2 \mathrm{~m}$; programmed temperature rise, $12{ }^{\circ} \mathrm{C}$

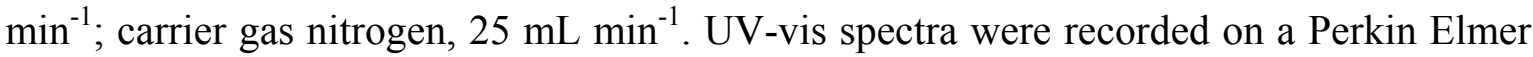
Lambda $19 \mathrm{UV} / \mathrm{VIS} / \mathrm{NIR}$ spectrometer. Emission spectra were performed in a semi-micro fluorescence cell $\left(\right.$ Hellma $\left.^{\circledR}, 104 \mathrm{~F}-\mathrm{QS}, 10 \times 4 \mathrm{~mm}, 1400 \mu \mathrm{L}\right)$ with a Varian Cary Eclipse spectrophotometer.

\section{Materials}

The preparations of 1-bromopyrene (2), 1,6-di- and 1,8-di-bromopyrene (3a and 3b), 1,3,6,8-tetrabromopyrene (4) from pyrene (1) have been previously reported [39]. 7-tertbutyl-1-(4,4,5,5-tetramethyl-1,3,2-dioxaborolan-2-yl)pyrene (5) [40] and 2-[9,9-bis(3methylbutyl)-9H-fluoren-2-yl]-4,4,5,5-tetramethyl[1,3,2]dioxaborolane (9) [41] were prepared by the reported procedures.

\subsection{Synthesis}

\subsubsection{Synthesis of 7-tert-butyl-1-(4,4,5,5-tetramethyl-1,3,2-dioxa-borolan-2-yl)pyrene (5).}

The compound 5 was prepared in $55 \%$ yield from 1-bromo-7-tert-butylpyrene following by the reported procedure [40] as a white solid. mp $155-157{ }^{\circ} \mathrm{C} .{ }^{1} \mathrm{H}$ NMR $\left(\mathrm{CDCl}_{3}, 300\right.$ MHz): $\delta_{\mathrm{H}}=1.49(\mathrm{~s}, 12 \mathrm{H}, \mathrm{Me}), 1.59(\mathrm{~s}, 9 \mathrm{H}, t \mathrm{Bu}), 8.02$ (d, $\left.J=9.0 \mathrm{~Hz}, 1 \mathrm{H}, \mathrm{Py}-\mathrm{H}\right), 8.06$ (d, $J$ $=9.6 \mathrm{~Hz}, 1 \mathrm{H}, \mathrm{Py}-\mathrm{H}), 8.10$ (d, $J=4.2 \mathrm{~Hz}, 1 \mathrm{H}, \mathrm{Py}-\mathrm{H}), 8.12$ (d, $J=2.7 \mathrm{~Hz}, 1 \mathrm{H}, \mathrm{Py}-\mathrm{H}), 8.21$ (d, $J=1.5 \mathrm{~Hz}, 1 \mathrm{H}, \mathrm{Py}-\mathrm{H}), 8.24$ (d, $J=1.8 \mathrm{~Hz}, 1 \mathrm{H}, \mathrm{Py}-\mathrm{H}), 8.49$ (d, $J=7.8 \mathrm{~Hz}, 1 \mathrm{H}, \mathrm{Py}-\mathrm{H})$, $9.02(\mathrm{~d}, J=9.3 \mathrm{~Hz}, 1 \mathrm{H}, \mathrm{Py}-\mathrm{H}) \mathrm{ppm}$; MS m/z: $384\left[\mathrm{M}^{+}\right]$; Anal. calcd. for $\mathrm{C}_{26} \mathrm{H}_{29} \mathrm{BO}_{2}$ (384.32) C, 81.26, H, 7.61. Found C, 81.24, H, 7.62.

2.1.2. Synthesis of 2-[9,9-bis(3-methylbutyl)-9H-fluoren-2-yl]-4,4,5,5-tetramethyl[1,3,2]dioxaborolane (9). 
Similarly, compound 9 was obtained from 2-bromo-9,9-bis(3-methylbutyl)-9H-fluorene [42] in $70 \%$ yield as a colorless powder. $\mathrm{mp} 86-88^{\circ} \mathrm{C}$ (Lit. [41] $\mathrm{mp} 86-88^{\circ} \mathrm{C}$ ).

\subsubsection{Synthesis of 1-(7-tert-butylpyren-1-yl)pyrene (6).}

1-Bromopyrene 2 (200 mg, $0.70 \mathrm{mmol})$, 7-tert-butyl-1-(4,4,5,5-tetramethyl-1,3,2dioxaborolan-2-yl)pyrene 5 (411mg, 1.07mmol), and $\mathrm{Pd}\left(\mathrm{PPh}_{3}\right)_{4}(109 \mathrm{mg}, 0.07 \mathrm{mmol})$ and aqueous 2.0 $\mathrm{M} \mathrm{K}_{2} \mathrm{CO}_{3}(2 \mathrm{~mL})$ were mixed in a flask containing argon saturated toluene $(15 \mathrm{~mL})$. The reaction mixture was stirred at $90{ }^{\circ} \mathrm{C}$ for $48 \mathrm{~h}$. After it was cooled to room temperature, the reaction mixture was quenched with saturated sodium bicarbonate solution and extracted with toluene $(50 \mathrm{~mL} \times 2)$. The combined organic extracts were dried with anhydrous $\mathrm{MgSO}_{4}$ and evaporated. The crude product was purified by column chromatography using hexane/dichloromethane (9:1) as eluent to provide 6 (236 mg, $72 \%)$ as pale yellow prisms. mp $278-280{ }^{\circ} \mathrm{C} ;{ }^{1} \mathrm{H} \mathrm{NMR}\left(\mathrm{CDCl}_{3}, 300 \mathrm{MHz}\right): \delta_{\mathrm{H}}=1.59(\mathrm{~s}$, $9 \mathrm{H}, t \mathrm{Bu}), 7.60-8.87(\mathrm{~m}, 17 \mathrm{H}, \mathrm{Ar}-H) \mathrm{ppm}$; MS m/z: $458\left[\mathrm{M}^{+}\right]$; Anal. calcd. for $\mathrm{C}_{36} \mathrm{H}_{26}$ (458.59) C, 94.29, H, 5.71. Found C, 94.28, H, 5.72.

\subsubsection{Synthesis of isomers of 1,6-bis(7-tert-butylpyren-2-yl)pyrene (7a) and 1,8-bis(7-tert-} butylpyren-2-yl)pyrene (7b).

Dibromopyrene (3a/3b) (200 mg, $0.56 \mathrm{mmol})$, 7-tert-butyl-1-(4,4,5,5-tetramethyl-1,3,2dioxaborolan-2-yl)pyrene 5 (422 mg, $1.40 \mathrm{mmol})$, and $\mathrm{Pd}\left(\mathrm{PPh}_{3}\right)_{4}(174 \mathrm{mg}, 0.112 \mathrm{mmol})$ and aqueous $2.0 \mathrm{M} \mathrm{K}_{2} \mathrm{CO}_{3}(2 \mathrm{~mL})$ were mixed in a flask containing argon saturated toluene $(50 \mathrm{~mL})$. The reaction mixture was stirred at $90{ }^{\circ} \mathrm{C}$ for $48 \mathrm{~h}$. After it was cooled to room temperature, the reaction mixture was quenched with saturated sodium bicarbonate solution and extracted with dichloromethane $(100 \mathrm{~mL} \times 2)$. The combined organic extracts were dried with anhydrous $\mathrm{MgSO}_{4}$ and evaporated. The crude product was washed with hot toluene and methanol to provide $7(268 \mathrm{mg}, 67 \%)$ as yellow prisms. $\mathrm{mp}>300{ }^{\circ} \mathrm{C} .{ }^{1} \mathrm{H}$ 
NMR $\left(\mathrm{CDCl}_{3}, 300 \mathrm{MHz}\right)$ : Not obtained; MS m/z: $714\left[\mathrm{M}^{+}\right]$; Anal. calcd. for $\mathrm{C}_{56} \mathrm{H}_{42}$ (714.93) C, 94.06, H, 5.93. Found C, 94.08, H, 5.92. The ${ }^{1} \mathrm{H}$ NMR spectrum of this compound was not obtained due to its limited solubility in $\mathrm{CDCl}_{3}$ solution. However, a strong blue fluorescence emission can be observed in solution.

\subsubsection{Synthesis of 1,3,6,8-tetrakis(7-tert-butylpyrene-1-yl)pyrene (8).}

1,3,6,8-tetrabromopyrene 4 (200 $\mathrm{mg}, 0.39 \mathrm{mmol})$, 7-tert-butyl-1-(4,4,5,5-tetramethyl1,3,2-dioxaborolan-2-yl)pyrene 5 (891 mg, $2.32 \mathrm{mmol})$, and $\mathrm{Pd}\left(\mathrm{PPh}_{3}\right)_{4}(243 \mathrm{mg}, 0.156$ mmol) and aqueous $2.0 \mathrm{M} \mathrm{K}_{2} \mathrm{CO}_{3}(2 \mathrm{~mL})$ were mixed in a flask containing argon saturated toluene $(50 \mathrm{~mL})$. The reaction mixture was stirred at $90{ }^{\circ} \mathrm{C}$ for $48 \mathrm{~h}$. After it was cooled to room temperature, the reaction mixture was quenched with saturated sodium bicarbonate solution and extracted with dichloromethane $(100 \mathrm{~mL} \times 2)$. The combined organic extracts were dried with anhydrous $\mathrm{MgSO}_{4}$ and evaporated. The crude product was purified by column chromatography using hexane/dichloromethane (5:1) as eluent to provide 8 (318 $\mathrm{mg}, 66 \%)$ as pale green prisms. $\mathrm{mp}>300{ }^{\circ} \mathrm{C} ;{ }^{1} \mathrm{H} \mathrm{NMR}\left(\mathrm{CDCl}_{3}, 300 \mathrm{MHz}\right): \delta_{\mathrm{H}}=1.55(\mathrm{~s}$, $36 \mathrm{H}, t \mathrm{Bu}), 7.70-8.25(\mathrm{~m}, 32 \mathrm{H}, \mathrm{Ar}-H), 8.27\left(\mathrm{~s}, 2 \mathrm{H}, \mathrm{Py}-H_{\mathrm{a}}\right), 8.38$ (s, 4H, Py- $\left.H_{\mathrm{b}}\right) \mathrm{ppm}$; MS m/z: $1227\left[\mathrm{M}^{+}\right]$; Anal. calcd. for $\mathrm{C}_{96} \mathrm{H}_{74}(1227.61) \mathrm{C}, 93.90, \mathrm{H}, 6.10$. Found $\mathrm{C}, 93.92, \mathrm{H}$, 6.08 .

2.1.6. Synthesis of 1,3,6,8-tetrakis-[9,9-bis(3-methylbutyl)-9H-fluoren-2-yl]pyrene (10).

1,3,6,8-Tetrabromopyrene 4 (200 mg, $0.39 \mathrm{mmol}$ ), 2-[9,9-bis(3-methylbutyl)-9H-fluoren2-yl]-4,4,5,5-tetramethyl[1,3,2]dioxaborolane 9 (1003 mg, $2.32 \mathrm{mmol})$, and $\mathrm{Pd}\left(\mathrm{PPh}_{3}\right)_{4}$ (243 mg, $0.156 \mathrm{mmol}$ ) and aqueous $2.0 \mathrm{M} \mathrm{K}_{2} \mathrm{CO}_{3}(2 \mathrm{~mL})$ were mixed in a flask containing argon saturated toluene $(50 \mathrm{~mL})$. The reaction mixture was stirred at $90{ }^{\circ} \mathrm{C}$ for $48 \mathrm{~h}$. After it was cooled to room temperature, the reaction mixture was quenched with saturated sodium bicarbonate solution and extracted with dichloromethane $(100 \mathrm{~mL} \times 2)$. The 
combined organic extracts were dried with anhydrous $\mathrm{MgSO}_{4}$ and evaporated. The crude product was purified by column chromatography using hexane/dichloromethane (9:1) as eluent to provide $8(452 \mathrm{mg}, 70 \%)$ as a pale green solid and recrystallization from $\mathrm{CHCl}_{3} / \mathrm{EtOH}(3: 1 \mathrm{v} / \mathrm{v})$ to afford 8 as pale yellow prisms. mp $276-278{ }^{\circ} \mathrm{C} ;{ }^{1} \mathrm{H} \mathrm{NMR}\left(\mathrm{CDCl}_{3}\right.$, $300 \mathrm{MHz}): \delta_{\mathrm{H}}=0.66-0.69(\mathrm{~m}, 48 \mathrm{H}, \mathrm{Me}), 1.23-1.35\left(\mathrm{~m}, 16 \mathrm{H}, \mathrm{CH}_{2}\right), 2.01-2.06(\mathrm{~m}, 24 \mathrm{H}$, $\mathrm{CH}_{2}$ and $\left.\mathrm{CH}\right), 7.31-7.41(\mathrm{~m}, 12 \mathrm{H}, \mathrm{Ar}-\mathrm{H}), 7.66-7.88(\mathrm{~m}, 16 \mathrm{H}, \mathrm{Ar}-H), 8.16\left(\mathrm{~s}, 2 \mathrm{H}, \mathrm{Py}-\mathrm{H}_{\mathrm{a}}\right)$, 8.19 (s, 4H, Py- $H_{\mathrm{b}}$ ) ppm; MS m/z: $1420\left[\mathrm{M}^{+}\right]$; Anal. calcd. for $\mathrm{C}_{108} \mathrm{H}_{122}$ (1420.12) C, 91.33, H, 8.67. Found C, 91.35, H, 8.66.

\subsubsection{1,3,6,8-tetrakis(4-methoxyphenyl)pyrene (12).}

1,3,6,8-Tetrabromopyrene 4 (200 mg, $0.386 \mathrm{mmol}$ ), 4-methoxyphenylboronic acid 11 (468 $\mathrm{mg}, 3.8 \mathrm{mmol})$, and $\mathrm{Pd}\left(\mathrm{PPh}_{3}\right)_{4}(243 \mathrm{mg}, 0.156 \mathrm{mmol})$ and aqueous $2.0 \mathrm{M} \mathrm{K}_{2} \mathrm{CO}_{3}(2 \mathrm{~mL})$ were mixed in a flask containing argon saturated toluene $(8 \mathrm{~mL})$. The reaction mixture was stirred at $90{ }^{\circ} \mathrm{C}$ for $48 \mathrm{~h}$. After it was cooled to room temperature, the reaction mixture was extracted with dichloromethane $(50 \mathrm{~mL} \times 2)$. The combined organic extracts were dried with anhydrous $\mathrm{MgSO}_{4}$ and evaporated. The crude product was purified by column chromatography using hexane/dichloromethane $(1: 1.5)$ as eluents to provide a pale powder and recrystallization from hexane afforded 12 (145 mg, $80 \%$ ) as a yellow prisms. mp 271$273{ }^{\circ} \mathrm{C} ;{ }^{1} \mathrm{H}$ NMR $\left(\mathrm{CDCl}_{3}, 300 \mathrm{MHz}\right): \delta_{\mathrm{H}}=3.92(\mathrm{~s}, 12 \mathrm{H}, \mathrm{OMe}), 7.08(\mathrm{~d}, J=8.8 \mathrm{~Hz}, 4 \mathrm{H}$, $A r-H), 7.59$ (d, $J=8.8 \mathrm{~Hz}, 4 \mathrm{H}, \operatorname{Ar}-H), 7.96$ (s, 2H, Py-H), 8.15 (s, 2H, Py- $H$ ); ${ }^{13} \mathrm{C}$ NMR $\left(\mathrm{CDCl}_{3}, 75 \mathrm{MHz}\right): \delta_{\mathrm{C}}=159.1,136.8,133.7,131.8,129.7,128.1,126.2,125.2,113.9,55.5$ ppm; MS m/z: $626\left[\mathrm{M}^{+}\right]$; Anal. calcd. for $\mathrm{C}_{44} \mathrm{H}_{34} \mathrm{O}_{4}$ (626.74) $\mathrm{C}, 84.32, \mathrm{H}, 5.47$. Found $\mathrm{C}$, 84.30, H, 5.48.

\subsection{Single-crystal X-ray diffraction measurements of $\mathbf{1 0}$ and $\mathbf{1 2 .}$}


Diffraction data for $\mathbf{1 0}$ and $\mathbf{1 2}$ were collected at low temperature on Bruker SMART APEX 2 and Rigaku R-Axis Rapid CCD diffractometers respectively. Data were corrected for absorption and Lp effects. Structures were solved by direct methods. The structures of 10 and 12 have two half molecules in their asymmetric units, both located on inversion centres; 12 also contains a chloroform molecule in addition to the two half molecules. In 10 atoms $\mathrm{C}(79)$ and $\mathrm{C}(80)$ \{major component 66(6)\% \} were modeled as disordered over two sets of positions, as were $\mathrm{C}(101), \mathrm{C}(102), \mathrm{C}(103)$ \{major component 50(3)\% $\%$. The diffraction data for 10 were weak and hence curtailed at $2 \theta=46^{\circ}$.

Crystallographic data (excluding structure factors) for the structures in this paper have been deposited with the Cambridge Crystallographic Data Centre as supplementary publication numbers CCDC 915428 (10) and 915429 (12). Copies of the data can be obtained, free of charge, on application to CCDC, 12 Union Road, Cambridge CB2 1EZ, UK [fax: 144-1223-336033 or e-mail: deposit@ccdc.cam.ac.uk]. Further details can be found in Table 1.

\section{Results and discussion}

\section{Synthesis}

1-Bromopyrene 2, 1,6-di-/1,8-di-bromopyrene $\mathbf{3 a / 3 b}$ and 1,3,6,8-tetrabromopyrene $\mathbf{4}$ were prepared by the bromination of pyrene 1 following the reported procedure [39]. The compound 5, prepared by following the reported procedure [40], underwent halogenlithium exchange of 1-bromo-7-tert-butylpyrene [40] with $n$-BuLi at $-78{ }^{\circ} \mathrm{C}$ in dry THF and then subsequent reaction of the anion with $\mathrm{B}(\mathrm{OMe})_{3}$ gave the corresponding pyrene boronic acid, from which esterification with pinacol afforded the boronic ester 5 (55\% yield) as a white solid. Similarly, compound 9 was prepared from 2-bromo-9,9-bis(3methylbutyl)-9H-fluorene [42] in a yield of $70 \%$ according to our previous report [41].

\section{Scheme 1}


A Suzuki cross-coupling reaction [43-45] was employed between the 1-bromopyrene 2 and the pyrene boronic ester 5 , under the improved reaction conditions reported in the literature [40], to afford the desired compound, 1-(7-tert-butylpyren-1-yl)pyrene 6 in $72 \%$ yield (Scheme 3). Similarly, the 1,3,6,8-tetrakis(7-tert-butylpyren-1-yl)pyrene 8 was obtained in $66 \%$ yield under the same conditions. Both 6 and 8 were successfully purified by flash column chromatography. On the other hand, the mixture of $\mathbf{3 a}$ and $\mathbf{3 b}$ was also reacted with pyrene boronic ester 5 to afford bis-pyrenyl-substituted pyrenes $\mathbf{7 a} / \mathbf{7 b}$ in $67 \%$ yield (Scheme 3). Although several attempted isolations of the mixture of 1,6-bisand 1,8-bis-pyrenyl-substituted pyrenes $\mathbf{7 a} / \mathbf{7} \mathbf{b}$ failed, the mixture of compounds $\mathbf{7 a} / \mathbf{7} \mathbf{b}$ was directly used to determine their photophysical properties. Similarly, 1,3,6,8-tetrakisfluorenyl-subsituted pyrene $\mathbf{1 0}$ and 1,3,6,8-tetrakis(4-methoxyphenyl)pyrene 12 [13] were prepared in 70 and $80 \%$ yields by the Suzuki cross-coupling reaction of $1,3,6,8$ tetrabromopyrene $\mathbf{4}$ with fluorene boronic ester $\mathbf{9}$ and 4-methoxyphenylboronic acid $\mathbf{1 1}$ following the reported literature procedure [42], respectively (Scheme 2 and 3).

\section{Scheme 2}

\section{Scheme 3}

The structures for these pyrene-based $\pi$-conjugated compounds 6-8, 10 and 12 were fully characterized on the basis of their ${ }^{1} \mathrm{H}$ NMR and mass spectra and by elemental analysis. In particular, due to its $D_{2 \mathrm{~d}}$ point-group symmetric structure, the ${ }^{1} \mathrm{H}$ NMR spectrum of the 1,3,6,8-tetrakispyrenyl-substituted pyrene $\mathbf{8}$ is simpler than those of asymmetrical compounds 6 and 7. For example, compound 1,3,6,8-tetrakis(7-tert-butyl-pyren-1yl)pyrene 8 displays two singlets at $\delta=8.27$ and $8.38 \mathrm{ppm}$ in the ratio of $1: 2$ for the pyrene ring protons at 2,7-positions and 4,5,9,10-positions, respectively. The pyrene ring protons of 6 and 7 appear in the region at $\delta=7.70-8.25$ ppm. Similarly, compound 1,3,6,8- 
tetrakis[9,9-bis(3-methylbutyl)-9H-fluoren-2-yl]pyrene 10 displays two singlets at $\delta=8.16$ and $8.19 \mathrm{ppm}$ in the ratio of 1:2 for the pyrene ring protons at the 2,7-positions and the 4,5,9,10-positions, respectively. The fluorene ring protons and the eight terminal methyl protons of 9,9-bis(3-methylbutyl) groups both appear in the region at $\delta=7.31-7.88 \mathrm{ppm}$ and at around $\delta=1.68 \mathrm{ppm}$ as a multiplet, respectively. The structures of $\mathbf{6}, 7 \mathbf{a} / \mathbf{7} \mathbf{b}, \mathbf{8}, 10$ and 12 were also established on the basis of their base peak molecular ions at $m / z 458\left[\mathrm{M}^{+}\right]$, $714\left[\mathrm{M}^{+}\right], 1227\left[\mathrm{M}^{+}\right], 1420\left[\mathrm{M}^{+}\right]$and $626\left[\mathrm{M}^{+}\right]$in their mass spectra, respectively.

Interestingly, these three types of pyrenyl-substituted pyrenes 6-8 and fluorenylsubstituted pyrene $\mathbf{1 0}$ are all stable solids that can be stored in air at room temperature for a prolonged period of time. Furthermore, these compounds have good solubility in common organic solvents including hexane and exhibit a high melting point of up to $270{ }^{\circ} \mathrm{C}$. However, the isomeric 1,6-bis-, and 1,8-bispyrenyl-substituted pyrenes $7 \mathbf{a}$ and $7 \mathbf{b}$ have limited solubility in organic solvents.

\section{X-Ray molecular structure and crystal packing}

The molecular structure of compound $\mathbf{1 0}$ was further confirmed by single crystal X-ray analysis. The crystals (pale yellow needles) were grown by slow evaporation of a concentrated chloroform solution. As a comparison, the crystals of 12 were also obtained from its concentrated chloroform solution. The crystallographic data for compounds $\mathbf{1 0}$ and $\mathbf{1 2}$ are summarized in Table 1.

Table 1. Summary of the crystal data of compounds $\mathbf{1 0}$ and $\mathbf{1 2 .}$

Figure 1. X-ray structure diagrams of compound 10 (i) top view; (ii) side view; (iii) packing diagrams.

Structure diagrams of $\mathbf{1 0}$ are shown in Figure 1 (i and ii). There are two half-molecules in ther asymmetric unit, each lying on an inversion centre The four fluorenyl groups (two 
unique in each molecule) are significantly twisted relative to the plane of the central pyrene core with twist angles of $80.4,37.1,79.9$, and $50.2^{\circ}$ for fluorene units containing $\mathrm{C}(9), \mathrm{C}(32), \mathrm{C}(63)$, and $\mathrm{C}(86)$ respectively. In general, the efficient $\pi$-stacking in emitting molecules could lead to extensive excimer formation in the solid state or thin film with low quantum yields of fluorescence. The crystal packing diagram of $\mathbf{1 0}$ is also shown in Figure 1 (iii). No $\pi \cdots \pi$ stacking was observed in this crystal due to the large steric hindrance arising from the bulky 9,9-bis(3-methylbutyl)-substituted fluorenyl groups attached to the pyrene ring at the 1-, 3-, 6-, and 8-positions. The pyrene to pyrne separation was $10.896 \AA$ In the crystals of 12, where the four phenyl groups are also significantly twisted by 47.0, 44.7, 47.8, and $74.8^{\circ}$ for rings containing $\mathrm{C}(9), \mathrm{C}(16), \mathrm{C}(31)$, and $\mathrm{C}(38)$ respectively, relative to the central pyrene core, somewhat shorter $\pi \cdots \pi$ separations were observed at 8.566 $\AA$, although these would not be described as $\pi \cdots \pi$ stacked (Figure 2). Thus, the studies indicate that these newly developed pyrenyl- and fluorenyl-functionalized pyrenes with less $\pi \cdots \pi$ stacking intermolecular interactions might indeed be advantageous as potential blue light-emitting materials in optoelectronic device applications.

Figure 2. X-ray structure diagram of compound 12 (i) top view; (ii) packing diagram; view parallel to $b$, highlighting the lack of $\pi \cdots \pi$ stacking.

\section{Photophysical properties}

The UV/Vis absorption and fluorescence spectra of these three types of pyrenyl-substituted pyrenes 6-8, the fluorenyl-substituted pyrene $\mathbf{1 0}$ and the phenyl-substituted pyrene $\mathbf{1 0}$ recorded in dichloromethane $\left(\mathrm{CH}_{2} \mathrm{Cl}_{2}\right)$ at $25{ }^{\circ} \mathrm{C}$ are shown in Figures 3 and 4 , respectively. The corresponding spectroscopic data are summarized in Table 2.

Figure 3. (a) Normalized UV-Vis absorption spectra of compounds 6, 7a/7b and 9; and (b) Normalized UV-Vis absorption spectra of compounds $\mathbf{1 0}$ and 12. All compounds are measured in dichloromethane at $\sim 10^{-5} \mathrm{M}$ concentration at $25^{\circ} \mathrm{C}$, compared with that of unsubstituted pyrene (1). 
Figure 4. (a) Normalized fluorescence emission spectra of compounds 6, 7a/7b and 8; and (b) Normalized fluorescence emission spectra of compounds $\mathbf{1 0}$ and 12. All compounds are measured in dichloromethane at $\sim 10^{-6} \mathrm{M}$ concentration at $25^{\circ} \mathrm{C}$, compared with that of unsubstituted pyrene (1).

Table 2. Photophysical data of compounds 6-8, 10, 12 and pyrene (1). ${ }^{\text {[a] }}$

As shown in Table 2 and Figure 3, the absorption spectra of these pyrenyl-substituted pyrenes 6-8 show a $\pi-\pi^{*}$ band at $\sim 349-396 \mathrm{~nm}$ and the absorption maxima of 6 (349 $\left.\mathrm{nm}\right)$ and $8(396 \mathrm{~nm})$ are significantly red-shifted $c a .13 \mathrm{~nm}$ and $c a .60 \mathrm{~nm}$ compared with that of the unsubstituted parent pyrene $1(336 \mathrm{~nm})$, respectively. Similarly, in the case of $\mathbf{7 a} / \mathbf{7 b}$, the absorption spectra maximum $(357 \mathrm{~nm})$ is red-shifted $c a .21 \mathrm{~nm}$ from that of pyrene $\mathbf{1}$. Thus, from the mono-substituted pyrene $\mathbf{6}$ to the tetrakispyrenyl-substituted pyrene $\mathbf{8}$, the absorption spectra gradually revealed a red-shift due to increasing $\pi$-conjugation, along with the increasing numbers of pyrenyl-substituents. Similar findings were observed in the tetrakis-fluorenyl-substituted pyrene $10\left(\lambda_{\max }=395 \mathrm{~nm}\right.$, red-shifted $\left.c a .59 \mathrm{~nm}\right)$ and the tetrakis-phenyl-substituted pyrene 12 [13] $\left(\lambda_{\max }=393 \mathrm{~nm}\right.$, red-shifted $\left.c a .57 \mathrm{~nm}\right)$ compared with the parent pyrene 1. A red-shift of $2 \mathrm{~nm}$ was detected in the UV/Vis absorption spectrum of $\mathbf{1 0}$ in comparison with that of $\mathbf{1 2}$, which is attributed to the larger $\pi$-conjugation system of fluorene versus benzene. Additionally, both tetrakispyrenylsubstituted pyrenes $\mathbf{8}$ and the tetrakisfluorenyl-substituted pyrene $\mathbf{1 0}$ have quite different absorption spectral characteristics due to the different substitutuents present. Indeed, the four benzene rings comprising the rigid pyrene ring provide a larger planar conjugated aromatic molecule than that formed by the biphenyl of the rigid fluorene ring. These newly obtained results further indicate that there are significant relationships between the photophysical properties of $\pi$-conjugated molecules and the numbers of substituents or substituent characteristics. 
When excited, dilute dichloromethane solutions of 6-8 exhibited high fluorescence from deep-blue to pure-blue emissions (Figure 4). In all of the fluorescence spectra, only one emission band was observed in the visible region, which indicates that the emission occurs from the lowest excited state with the largest oscillator strength. The emission spectra reveal systematic bathochromic red-shifts in line with the increase in the conjugation arising from the increasing numbers of substituents compared with the parent pyrene 1 . In the present pyrenyl-substituted pyrenes (6-8), the order is $\mathbf{6}<\mathbf{7 a} / \mathbf{7 b}<\mathbf{8}$, implying that the energy gap between ground state and excited state decreases in this order (Table 2). For example, the emission maxima of the pyrenyl-substituted pyrenes $\mathbf{6}, \mathbf{7 a} / \mathbf{7 b}$, and $\mathbf{8}$, consecutively shifted to longer wavelengths at 432, 451 and $465 \mathrm{~nm}$ respectively (Figure 4a), in a manner similar to their absorption maxima. These results were also observed in some carbazole-based dendrimers [46] and several phenylethynyl-substituted pyrene derivatives $[47,48]$. Similar findings were observed in the tetrakisfluorenyl-substituted pyrene $10\left(\lambda_{\max }=456 \mathrm{~nm}\right.$, red-shifted $\left.c a .82 \mathrm{~nm}\right)$ and the tetrakis-phenyl-substituted pyrene 12 [13] $\left(\lambda_{\max }=432 \mathrm{~nm}\right.$, red-shifted $\left.c a .58 \mathrm{~nm}\right)$, in a manner similar to their absorption maxima (Figure 4b).

The fluorescence quantum yields $\left(\Phi_{\mathrm{f}}\right)$ of $\mathbf{6 - 8}$ and $\mathbf{1 0}$ recorded in dichloromethane are listed in Table 2, along with their absorption $\left(\mathrm{A}_{\max }\right)$ and emission $\left(\lambda_{\max }\right)$ maxima. The quantum yield $\Phi_{\mathrm{f}}$ values of $\mathbf{6 - 8}$ and $\mathbf{1 0}$ were found to be in the range $0.75-0.99$ relative to that of 9, 10-diphenylanthrathcene (0.90 in cyclohexane) [49].

In order to obtain detailed electronic spectroscopic properties of these pyrenyl-substituted pyrenes, the influence of solvents on the UV-vis absorption and fluorescence emissions were investigated. The 1-pyrenyl-substituted pyrene 6 and 1,3,6,8-tetrakis-pyrenylsubstituted pyrene 8, were selected as representative compounds, and their optical absorption and emission spectroscopic data measured in various solvents are listed in Table 3. 
Figure 5. (i) Normalized UV-Vis absorption spectra of 6 and (ii) Normalized UV-Vis absorption spectra of 8 recorded in (a) cyclohexane (CCH), (b) tetrahydrofuran (THF), (c) dichloromethane (DCM), (d) chloroform $\left(\mathrm{CHCl}_{3}\right)$, and (e) N,N-dimethylformamide (DMF) at $\sim 10^{-5} \mathrm{M}$ concentration at $25^{\circ} \mathrm{C}$.

Figure 6. (i) Normalized emission spectra of $\mathbf{6}$ and (ii) Normalized emission spectra of 8 recorded in (a) cyclohexane (CCH), (b) tetrahydrofuran (THF), (c) dichloromethane (DCM), (d) chloroform $\left(\mathrm{CHCl}_{3}\right)$, and (e) $N, N$-dimethylformamide (DMF) at $\sim 10^{-6} \mathrm{M}$ concentration at $25^{\circ} \mathrm{C}$.

Table 3. Optical absorption and emission spectroscopic data for compounds $\mathbf{6}$ and $\mathbf{8}$ in various solvents at $25^{\circ} \mathrm{C} .^{\text {[a] }}$

The solvatochromic effect not only depends on the molecular structure, but also depends on the nature of the chromophore, and the solvents [49]. We observed a slight positive solvatochromism in both their absorption and their emission spectra (Table 3) for $\mathbf{6}$ and $\mathbf{8}$. For instance, for $\mathbf{6}$, only a very slight positive solvatochromic shift in the $\pi-\pi *$ absorption band from 348 to $350 \mathrm{~nm}$ (Figure 5(i), $\Delta \lambda_{\text {abs }}=2 \mathrm{~nm}$ ) was observed along with a change in solvent from non-polar cyclohexane $(\mathrm{CCH})$ to polar $N, N$-dimethylformamide (DMF). Similarly, in the case of emission for $\mathbf{6}$, a small positive solvatochromism behavior was also observed with increasing solvent polarity; the emission spectrum of $\mathbf{6}$ was observed with a peak around $425 \mathrm{~nm}$ in cyclohexane. A broad and red-shifted emission of 6 was observed with only one peak at $\lambda_{\max }=449 \mathrm{~nm}\left(\Delta \lambda_{\mathrm{emi}}=24 \mathrm{~nm}\right)$ in solvent of high polarity, namely DMF (Figure 6(i)). Similar results were also observed for 8 in both the absorption spectra and emission spectra (Figure 5(ii) and 6(ii)). We have also used a Mataga-Lippert plot to determine the line relationship of the Stokes shift ( $\Delta$ vst) against the solvent parameter $\Delta f-(\varepsilon, n)[50]$. Mataga-Lippert plots of $\mathbf{6}$ and $\mathbf{8}$ are shown in Figure 7. The slope gives the variation of dipole moment upon excitation. The linear relationship suggests the presence of just one excited state. 
Figure 7. Mataga-Lippert plots of 6 (top) and 8 (bottom) (a: cyclohexane; b:

dichloromethane; c: tetrahydrofuran; d: dimethylformamide; and e: acetonitrile).

These results indicated that the $\mu_{\mathrm{e}}$ (dipole moment of $\mathbf{6}$ in the excited state) should be a little larger than the $\mu_{\mathrm{g}}$ (the dipole moment of $\mathbf{6}$ in the ground state) because a positive solvatochromic effect was observed in the absorption spectra and emission spectra $[51,52]$. Although the dipole moments of $\mathbf{8}$ in either the ground or excited states are indeed zero because they are centro-symmetric in the ideal $C_{2 h}$ symmetry, these current results obtained above indicated that the $Q_{e}$ (the quadrupole moments of 8 in the excited state) should be larger than the $Q_{g}$ (the quadrupole moments of $\mathbf{8}$ in the ground state) because positive solvatochromic effects were observed in both the absorption spectra and the emission spectra. This implies that there is a change in the quadropole moment upon excitation [53]. On the other hand, the fact that the solvatochromic effect is more important for emission than for absorption, suggests that these current compounds are more solvated in the excited state than in the ground state [54].

\section{Conclusions}

Three types of pyrenyl-substituted pyrenes $\mathbf{6 - 8}$ and 1,3,6,8-tetrakis-fluorenyl-substituted pyrene 10 have been synthesized in high yield by modified Suzuki cross-coupling reactions. Photophysical studies of 6-8 indicated that there is a significant effect on the UV-vis absorption spectra and emission spectra on increasing the number of pyrenyl substituents. Compounds 6-8 and 10 emit very bright fluorescence in solution from deepblue to pure-blue respectively $\left(\Phi_{\mathrm{f}} \approx 0.75-0.99\right.$ in $\left.\mathrm{CH}_{2} \mathrm{Cl}_{2}\right)$ with high stability. A slight solvatochromic effect was observed in 6-8 and can be explained in terms of these current compounds 6-8 being more solvated in the excited state than in the ground state. Similar results were also obtained from the 1,3,6,8-tetrakis-fluorenyl-substituted pyrenes $\mathbf{1 0}$. It is worth mentioning that we have succeeded in improving the solubility problems of $1,3,6,8$ tetrakisarylpyrenes, such as 1,3,6,8-tetrakis(4-methoxyphenyl)pyrene 12, for the common 
organic solvents by the introduction of 7-tert-butylpyrene-1-yl and 9,9-bis(3-methylbutyl)9H-fluoren-2-yl groups in the pyrene ring. These molecules are exciting new materials that combine excellent optical features and improved thermal stability. Thus, applications in OLEDs can be anticipated and further explorations into this area are currently under study in our laboratory.

\section{Acknowledgments}

This work was performed under the Cooperative Research Program of "Network Joint Research Center for Materials and Devices (Institute for Materials Chemistry and Engineering, Kyushu University)".

\section{References}

[1] T.C. Wang, S.A. Van Slyke, Appl. Phys. Lett. 51 (1987) 913.

[2] Y.R. Sun, N.C. Giebink, H. Kanno, B.W. Ma, M.E. Thompson, S.R. Forrest, Nature 440 (2006) 908.

[3] F. So, J. Kido, P. Burrows, MRS Bull. 33 (2008) 663.

[4] S. Reineke, F. Linder, G. Schwartz, N. Seidler, K. Walzer, B. Lussem, K. Leo, Nature 459 (2009) 234.

[5] Q.-C. Zhou, A.-J. Qin, Q.-G. He, G.-T. Lei, L.-D. Wang, Y.Q.C. Teng, F.-T. Bai, J. Lumin. 122 (2007) 674.

[6] X.-Y. Jiang, Z.-L. Zhang, X.-Y. Zheng, Y.-Z. Wu, S.-H. Xu, Thin Solid Films 401 (2001) 251 .

[7] B. Balaganesan, W.-J. Shen, C.H. Chen, Tetrahedron Lett. 44 (2003) 5747.

[8] Y. Shibano, T. Umeyama, Y. Matano, H. Imahori, Org. Lett. 10 (2007) 1971.

[9] Y.-L. Liao, C.-Y. Lin, K.-T. Wong, T.-H. Hou, W.-Y. Hung, Org. Lett. 10 (2007) 4511. 
[10] K.R.J. Thomas, J.-T. Lin, Y.-T. Tao, C.-W. Ko, J. Am. Chem. Soc. 123 (2001) 9404.

[11] G. Venkataramana, S. Sankararaman, Eur. J. Org. Chem. (2005) 4162.

[12] G. Venkataramana, S. Sankararaman, Org. Lett. 8 (2006) 2739.

[13] V.D. Halleux, J.-P. Calbert, P. Brocorens, J. Cornil, J.-P. Declercq, J.-L. Bredas, Y. Greets, Adv. Funct. Mater. 14 (2004) 649.

[14] J. N Moorthy, P. Natarajin, P. Venkatakrishnan, D.-F. Huang, T.J. Chow, Org. Lett. 9 (2007) 5215.

[15] C. Modrakowski, S.C. Flores, M. Beinhoff, A.D. Schlüter, Synthesis (2001) 2143.

[16] J.-Y. Hu, M. Era, M.R.J. Elsegood, T. Yamato, Eur. J. Org. Chem. (2010) 72.

[17] J.-Y. Hu, X.-L. Ni, X. Feng, M. Era, M.R.J. Elsegood, S.J. Teat, T. Yamato, Org. Biomol. Chem. 10 (2012) 2255.

[18] M. Beinhoff, W. Weigel, M. Jurczok, W. Rettig, A.D. Schlüter, Eur. J. Org. Chem. (2001) 3819.

[19] H. Shimizu, K. Fujimoto, M. Furusayo, H. Maeda, Y. Nanai, K. Mizuno, M. Inouye, J. Org. Chem. 72 (2007) 1530.

[20] A.C. Benniston, A. Harriman, D.J. Lawrie, S.A. Rostron, Eur. J. Org. Chem. (2004) 2272 .

[21] E. Rivera, M. Belletete, X.-X. Zhu, G. Durocher, R. Giasson, Polymer 43 (2002) 5059.

[22] K.-T. Wong, Y.-Y. Chien, R.-T. Chen, C.-F. Wang, Y.-T. Lin, H.-H. Chiang, P.-Y. Hsieh, C.-C. Wu, C.-H. Chou, Y.-O. Su, G.-H. Lee, S.-M. Peng, J. Am. Chem. Soc. $124(2002) 11576$.

[22] G. Klaerner, R.D. Miller, Macromolecules 31 (1998) 2007.

[23] U. Lemmer, S. Hein, R.F. Mahrt, U. Scherf, M. Hopmeir, U. Wiegner, R.O. Göbel, K. Müllen, H. Bassler, Chem. Phys. Lett. 240 (1995) 371.

[24] S.A. Jenekhe, J.A. Osaheni, Science 265 (1994) 765. 
[25] K.-T. Wong, Y.-Y. Chien, R.-T. Chen, C.-F. Wang, Y.-T. Lin, H.-H. Chiang, P.-Y. Hsieh, C.-C. Wu, C.-H. Chou, Y.-O. Su, G.-H. Lee, S.-M. Peng, J. Am. Chem. Soc. $124(2002) 11576$.

[26] D. Katsis, Y.H. Geng, J.J. Ou, S. W. Culligan, A. Trajkovska, S.H. Chen, L. Rothberg, J. Chem. Mater. 14 (2002) 1332.

[27] Y. Geng, S.W. Culligan, A. Trajkovska, J.U. Wallace, S.H. Chen, Chem. Mater. 15 (2003) 542.

[28] S.W. Culligan, Y. Geng, S.H. Chen, K. Klubek, K.M. Vaeth, C.W. Tang, Adv. Mater. 15 (2003) 1176.

[29] C.-C. Wu, Y.-T. Lin, K.-T. Wong, R.-T. Chen, Y.-Y.Chien, Adv. Mater. 16 (2004) 61.

[30] Z.H. Li, M.S. Wong, H. Fukutani, Y. Tao, Chem. Mater. 17 (2005) 5032.

[31] T. Yasuda, K. Fujita, T. Tsutsui, Chem. Mater. 17 (2005) 264.

[32] W.-Y. Lai, R. Zhu, Q.-L. Fan, L.-T. Hou, Y. Cao, W. Huang, Macromolecules 39 (2006) 3707.

[33] J.R. Lakowicz, Principles of Fluorescence Spectroscopy; Plenum Press: New York, 1999.

[34] A. Knorr, J. Daub, Angew. Chem. Int. Ed. 34 (1995) 2664.

[35] Z. Shen, R. Prochazka, J. Daub, N. Fritz, N. Acar, S. Schneider, Phys. Chem. Chem. Phys. 5 (2003) 3257.

[36] D. Rausch, C. Lambert, Org. Lett. 8 (2006) 5037.

[37] W.-L. Yu, J. Pei, W. Huang, A.J. Heeger, Adv. Mater. 12 (2000) 828.

[38] K.-T. Wong, Y.Y. Chien, R.T. Chen, C.F. Wang, Y.T. Lin, H.H. Chiang, P.Y. Hsieh, C.C. Wu, C.H. Chou, Y.O. Su, G.P. Lee, S.M. Peng, J. Am. Chem. Soc. 124 (2002) 11576.

[39] J-Y. Hu, F. Xing, N. Seto, X. Zeng, Z. Tao and T. Yamato, Journal of Molecular Structure, 1013 (2013) 19. 
[40] T.M. Figueira-Duarte, S.C. Simon, M. Wagner, S.I. Druzhinin, K.A. Zachariasse, K. Müllen, Angew. Chem. Int. Ed. 47 (2008) 10175.

[41] J. Hu, H. Hiyoshi, J. Do and T. Yamato, J. Chem. Research (2010) 278.

[42] W.-L. Yu, J. Pei, Y. Cao, W.J. Huang, A. Heeger, Chem. Commun. (1999) 1837.

[43] N. Miyaura, T. Yanagi, A. Suzuki, Synth. Commun. 11 (1981) 513.

[44] N. Miyaura, K. Yamada, H. Suginome, A. Suzuki, J. Am. Chem. Soc. 107 (1985) 972.

[45] N. Miyaura, A. Suzuki, Chem. Rev. 95 (1995) 2457.

[46] R.M. Adhikari, R. Mondal, B.K. Shah, D.C. Neckers, J. Org. Chem. 72 (2007) 4727.

[47] H. Maeda, T. Maeda, K. Mizuno, K. Fujimoto, H. Shimizu, M. Inouye, Chem.- Eur. J. 12 (2006) 824.

[48] H.M. Kim, Y.O. Lee, C.S. Lim, J.S. Kim, B.R. Cho, J. Org. Chem. 73 (2008) 5127.

[49] J.C. Sciano, Handbook of Organic Photochemistry; CRC Press: Boca Raton, FL, 1989; Vol. 1, p 231.

[50] E.M.S. Castanheira, M.S.D. Carvalho, D.J.G. Soares, P.J.G. Coutinho, R.C. Calhelha, M.-J. R.P. Queiroz, J. Fluoresc. 21 (2011) 911.

[51] C. Reichardt, Chem. Rev. 94 (1994) 2319.

[52] T. Soujanya, R.W. Fessenden, A. Samanta, J. Phys. Chem. 100 (1996) 3507.

[53] J.D. Jackson, (Ed.), Classical Electrodynamics, John Wiley \& Sons, 1975.

[54] S. Chew, P. Wang, Z. Hong, H.L. Kwong, J. Tang, S. Sun, C.S. Lee, S.-T. Lee, J. Lumin. 124 (2007) 221. 